Stoker, M. G. P. \& Ross, R. W. (1958). J. gen. Microbiol. 19, 250-266

\title{
Quantitative Studies on the Growth of Herpes Virus in HeLa Cells
}

\author{
By M. G. P. STOKER AND R. W. ROSS \\ Department of Pathology, University of Cambridge
}

\begin{abstract}
SUMMARY: Less than a tenth of the pock-forming particles of the HFEM strain of herpes virus are able to initiate infection in HeLa cells, even after passage in these cells. The pock-forming virus attaches firmly to the cells but most of it remains susceptible to antiserum and presumably does not penetrate the cell. A small proportion of virus initiates infection in the HeLa cells, and, after exposure to more than one HeLa infectious particle/cell, new virus first appears in the cell fraction $12 \mathrm{hr}$. after infection, and $4 \mathrm{hr}$. later virus is released into the medium. Virus in the cell fraction can be detected either by disruption of the cells, or simply by removing the cells from the glass with ethylenediaminetetra-acetic acid (EDTA) or saline. This 'EDTA fraction' may contain virus released from the cell surface. An attempt was made to determine the number of virus-yielding cells, by inoculation of whole cells on to the chick chorioallantoic membrane. The proportion which yielded virus was lower than would be expected from the input of HeLa-infectious virus. After removal of superficially attached virus with antiserum, it was not possible to detect infective virus during the latent period in the majority of cells which ultimately released virus.
\end{abstract}

Herpes virus is well known as a cause of latent infection, and it is our interest in latency which has prompted further investigation of the growth of this virus. Previous work on herpes virus multiplication has been carried out in the chorioallantoic membrane cavity of fertile hens' eggs (Scott, Coriell, Blank \& Gray, 1953; Wildy, 1954; Yoshino \& Taniguchi, 1956 $a, b)$ and in explants of rabbit cornea (Scott, Burgoon, Coriell \& Blank, 1953). In recent years a more quantitative approach has been possible through the use of cell suspensions and monolayer cultures, and growth studies have been reported by Gostling \& Bedson (1956) and Gostling (1956) in chick embryo cells, and more recently by Kaplan (1957) in rabbit kidney cells. We have studied the growth of herpes virus in HeLa cells because of the desirability of propagating cells indefinitely when studying latent infection. HeLa cells are also convenient because they are suitable for isolation of cell clones, and for study of virus release from isolated single cells.

This paper describes some aspects of virus growth in monolayer cultures of HeLa cells. Studies on plaque formation in HeLa cells (Farnham, 1958), cytological observations (Ross \& Orlans, 1958), chemical changes (Newton \& Stoker, 1958), electron microscope studies (Stoker, Smith \& Ross, 1958) and single cell experiments (Wildy, P., Stoker, M. G. P. \& Ross, R. W., unpublished) will be given in other communications. 


\section{METHODS}

Propagation of line of HeLa cells. Human epidermoid carcinoma cells (strain HeLa, Gey) were maintained as stationary cultures on one of the flat sides $(3.0 \times 10 \cdot 0 \mathrm{~cm}$.) of $200 \mathrm{ml}$. Pyrex babies' feeding bottles. Growth medium consisted of human serum $20 \%(\mathrm{v} / \mathrm{v})$, lactalbumin hydrolysate $0.5 \%(\mathrm{w} / \mathrm{v})$, and phenol red $0.002 \%(\mathrm{w} / \mathrm{v})$, in Gey's (1949) saline, with 100 units penicillin and $100 \mu \mathrm{g}$. streptomycin $/ \mathrm{ml}$. For subculture cells were washed three times with calcium- and magnesium-free buffered saline (solution $\mathbf{A}$ of Dulbecco \& Vogt, 1954) and removed from the glass by treatment with $1 / 20,000(w / v)$ sodium ethylenediaminetetra-acetic acid (EDTA) for $20 \mathrm{~min}$. at $37^{\circ}$. Alternatively, cultures were treated with $1 / 5000(w / v)$ sodium EDTA without previous washing. For virus inoculation continuous sheets of cells were grown in babies' feeding bottles or in $1.7 \times 14 \mathrm{~cm}$. Pyrex test tubes on a rectangular flattened area of $1.0 \times 3.7 \mathrm{~cm}$. Before use the cell sheets were washed with phosphate buffered saline (PBS; Dulbecco \& Vogt, 1954) to remove herpes antibody in the growth medium.

Virus experiments were carried out in the following medium: rabbit serum $5 \%(\mathrm{v} / \mathrm{v})$, lactalbumin hydrolysate $0.5 \%(\mathrm{w} / \mathrm{v})$ and phenol red $0.002 \%(\mathrm{w} / \mathrm{v})$ in Gey's (1949) saline, with penicillin 100 units and streptomycin $100 \mu \mathrm{g} . / \mathrm{ml}$. Reference in the text to medium without further specification, means that this rabbit serum medium was used for experiments.

Cell counts were made in a haemocytometer chamber after pipetting the cells to remove clumps. For rough estimates 100 or more cells were counted in four $1 \mathrm{~mm}$. squares. For enumeration of the proportion of yielding cells eight $1 \mathrm{~mm}$. squares containing a total of 200 or more cells were counted.

Virus strain. The Melbourne line of the HF strain of herpes virus (HFEM strain), which has undergone long adaptation to eggs and mice, was kindly supplied by Dr Peter Wildy as infected egg fluid. The virus was propagated by serial passage in HeLa cells, and seed suspensions were prepared at the eighth or subsequent passage from culture fluids harvested 3-4 days after inoculation with a large dose of virus, when a generalized cytopathic effect was marked. These seed suspensions, which contained between $10^{7}$ and $10^{8}$ pock units $/ \mathrm{ml}$, were centrifuged at $700 \mathrm{~g}$ for $10 \mathrm{~min}$. and dispersed in small volumes, which were stored at $-70^{\circ}$ without detectable loss of infectivity.

Virus assay. Infectivity was mostly determined by pock counts on the chorioallantoic membrane (CAM) of fertile hens' eggs. With the strain of virus used, this method gave easily countable lesions, and titres were obtained which were 10 or more times the $50 \%$ end-point as determined by tube titrations in HeLa cells, or the titre determined by plaque counts in HeLa cells (Farnham, 1958). For titration the virus suspensions were diluted in distilled water, $10 \%$ horse serum in meat digest broth, or rabbit serum medium, with no appreciable difference in titres obtained.

The chorioallantoic membranes of 12- or 13-day-old white Leghorn chick embryos were inoculated with $0 \cdot 2 \mathrm{ml}$. volumes after preparation by the punch method of Nadaje, Tamm \& Overman (1955), but the following modification 
was introduced. One hour after the inoculation the eggs were tipped into a vertical position with the original air space uppermost, and the holes were sealed with wax. In this way, air enters the original air space and the false air space is obliterated, the chorioallantoic membrane returning to its original position under the shell membrane. This reduces non-specific lesions and spreads the inoculum widely and evenly so that a larger number of pocks can be counted on each membrane. Two days after inoculation the egg was deembryonated and almost the whole membrane was harvested, washed and spread for counting. Five or more eggs were inoculated with each dilution. The mean count/membrane was determined from groups of four or more eggs with between 5 and 150 pocks/membrane. The mean count on four or five membranes generally had a standard error between $10 \%$ and $20 \%$. No increase in the number of pocks resulted when the eggs were incubated for 3 instead of 2 days, and the extra day led to overlapping when there were 100 or more pocks/membrane. Eggs from two other breeds of fowl showed the same sensitivity as the white Leghorn breed used.

Dose-response curves showed a linear relationship up to 150 pocks/membrane when counts were made at 2 days (Fig. 1 ). The absence of serious overlapping of pocks, even with this large number on one membrane, is probably due to the small size of the herpes lesion and wide dispersal of virus by the replacement of the membrane against the shell. Titres obtained by pock count are referred to in terms of 'pock units'.

Though the more sensitive pock technique is satisfactory for investigation of the development of virus during the growth cycle, it was desirable to express virus input in terms of HeLa cell infectivity. At the time this could only be measured as the $50 \%$ end-point and was variable when compared to the egg infectivity. Subsequently, however, Farnham (1958) has developed a reliable technique for counting microscopic plaques in HeLa cell monolayers under fluid medium, and she has found that the plaque-forming titre of the HFEM strain, after thirty-four passages in HeLa cells, is $7 \cdot 5 \%$ of the pock-forming titre $(\mathrm{egg} / \mathrm{HeLa}$ ratio $=13)$. Under certain conditions $60 \%$ of the plaqueforming units (pfu) are adsorbed in $1 \mathrm{hr}$. and $80 \%$ in $2 \mathrm{hr}$. from a thin layer of fluid.

From these figures it has been possible, retrospectively, to calculate the approximate virus input in pfu from the titre of the inoculum in pock units. The deduction is subject to the criticism that the ratio and rate of adsorption may vary from one virus preparation to another especially during passage in HeLa cells. Nevertheless, the original egg grown HFEM strain (Pock/HeLa ratio $=7$ ) has a slightly higher relative infectivity for HeLa cells than the same strain passaged 34 times in these cells. It therefore appears that passage in HeLa cells does not markedly change the infectivity of the virus for these cells.

Stability of virus. Because herpes virus is known to lose infectivity rapidly through thermal inactivation, it was necessary to determine its stability in the various media and fluid used, and at the temperatures of the experiments. No significant reduction in infectivity occurred when the virus was stored in medium at $-70^{\circ}$ for 3 months or at $4^{\circ}$ for 1 month. Storage at $-20^{\circ}$, however, 
reduced the infectivity more than tenfold in 2 weeks. Ten cycles of freezing at $-70^{\circ}$ and thawing at $37^{\circ}$ did not reduce the infectivity when the virus was suspended in medium. Ten cycles of freezing and thawing in distilled water, however, did lower the titre more than tenfold. Exposure to sodium EDTA $(1 / 2000$ to $1 / 20,000)$ for $2 \mathrm{hr}$. at $37^{\circ}$ did not affect the virus.

The thermal inactivation of the virus is to be the subject of a separate study (Miss A. E. Farnham, unpublished). In medium at $37^{\circ}$ the virus begins to lose infectivity after $1 \mathrm{hr}$., the titre is halved in $6.5 \mathrm{hr}$., and there is more than a tenfold reduction in $\mathbf{2 4} \mathrm{hr}$. During experiments preparations containing virus were kept at $4^{\circ}$ until titrated and were only handled at room temperature or $37^{\circ}$ for minimal essential periods.

Antisera. Herpes antisera were obtained by selecting specimens from human blood donors; such antisera, when diluted 1/10 in medium had neutralization indices of about $10^{3}$ as determined by pock counts after virus serum interaction for $30 \mathrm{~min}$. at $37^{\circ}$. Alternatively rabbit antisera of about the same strength were prepared by corneal inoculation of rabbits followed by hyperimmunization with infected rabbit brain suspension.

Growth experiments. When repeated cell samples were required, flat-sided tubes containing monolayers of about $10^{5} \mathrm{HeLa}$ cells were inoculated with approximately $10^{7}$ pock units (estimated $10^{5 \cdot 87} \mathrm{HeLa}$ pfu) of virus in $1 \mathrm{ml}$. medium. After 1-2 hr. at $37^{\circ}$ the inoculum was discarded and residual extracellular virus was removed by the following standard procedure. The cells were washed three times with 5-10 ml. volumes of PBS, then exposed to $1.5 \mathrm{ml}$. of herpes immune serum (10\% in medium) for 30 min., washed once with PBS, re-exposed to fresh immune serum for $30 \mathrm{~min}$., washed three times with PBS to remove antiserum and then replaced under medium. At various time intervals thereafter, groups of four tubes were taken for sampling. The medium was removed, the cells washed three times in calcium magnesium free PBS and removed from the glass by exposure to $1 / 20,000$ sodium EDTA. Clumps were broken by pipetting, and the cells were counted. Some of the suspension of intact cells was diluted in medium, with siliconed pipettes, to give suspensions with $10^{2}$ and $10^{3}$ cells/egg, and inoculated on to the chorioallantoic membrane to show the number of pock-forming cells. A sample of the suspension was also centrifuged leaving the cell-free EDTA fraction for virus assay. The remainder of the cell suspension was also diluted and was disrupted by ten cycles of freezing at $-70^{\circ}$. The whole of the resulting debris was inoculated into the chorioallantoic membrane for assay of intracellular virus. When repeated samples of cells were not required, growth experiments were carried out in feeding bottles containing monolayers of 2 to 5 million cells. These were generally inoculated with about $10^{8}$ pock units of virus (estimated $10^{6.87} \mathrm{HeLa}$ pfu) in $2 \mathrm{ml}$. medium. After adsorption, washing was carried out as for tubes but with $50 \mathrm{ml}$. quantities of PBS and $20 \mathrm{ml}$. quantities of immune serum in medium. The results of the growth experiments are generally expressed in relation to numbers of cells. After exposure to large doses of the HFEM strain of herpes virus, cell counts in fact remained relatively constant for the duration of the experiment. 


\section{RESULTS}

\section{General characteristics of growth curve}

Monolayers of $10^{5}$ cells in a number of tubes were each exposed to $10^{7.87}$ pock units (estimated $10^{6.74} \mathrm{HeLa}$ pfu) of virus for $2 \mathrm{hr}$. and were then washed and treated with immune serum to remove excess virus as described. The medium, EDTA fraction, and cells (disintegrated by freezing and thawing) were sampled from the pooled contents of sets of four tubes at successive time intervals, and assayed for infective virus. Whole cell suspensions taken in the latent period were also assayed to determine the proportion of cells which formed pocks, through release of virus.

In the first experiment cells were disrupted by freezing and thawing in distilled water, a procedure subsequently shown to reduce virus infectivity, so the virus content of medium and EDTA fraction alone are shown in Fig. 2. A second experiment in Fig. 3, with fewer samples, was carried out under the same conditions but with the cells disrupted by freezing and thawing in medium, which does not lower virus infectivity.

These results show first, that following washing and immune serum treatment, some virus still remains in the medium, EDTA fraction and cell debris. It comprises, however, less than $0.005 \%$ of the original inoculum and represents only 1 pock unit/55 cells (Fig. 2 ) or 1 pock unit/125 cells (Fig. 3). This residual virus in the latent period remains approximately the same or falls slightly until after $9 \mathrm{hr}$. At $12 \mathrm{hr}$. there is a marked increase in the virus content of the cell debris and EDTA fraction, but no release of new virus into the medium. The virus content of the medium does not commence to rise until $16 \mathrm{hr}$. There is thus a delay of 3-6 hr. between appearance of new virus in the cells and release into the medium. The number of pock-forming cells compared to the total is also shown and is unexpectedly low, but this method of estimating the proportion of cells infected will be discussed later in the results.

To prevent loss of virus through re-attachment, and to investigate multiplication after $26 \mathrm{hr}$., uncomplicated by second cycles of infection, a further experiment was performed in which the cell suspension was diluted in the latent period to prevent re-attachment. The experiment was set up as before with sampling of medium and EDTA fraction, except that $5 \mathrm{hr}$. after infection, and following the standard washing and immune serum treatment, $6 \times 10^{4}$ cells from each of two tubes were removed with EDTA, diluted in $20 \mathrm{ml}$. medium, and incubated in a feeding bottle. A control with this number of normal cells diluted and added to a feeding bottle was exposed to virus after $24 \mathrm{hr}$. and produced no significant fall in pock count after a further $2 \mathrm{hr}$., indicating that attachment under these conditions was very slow.

The results in Fig. 4 show that the medium from the diluted cells contained more infective virus than the medium from the intact monolayers, suggesting that release from the monolayers is in fact hampered by re-attachment. Furthermore, the concentration of virus from monolayers and the diluted cells was not reduced $23 \mathrm{hr}$. later, $50 \mathrm{hr}$. after infection. Since thermal inactivation 
would have decreased the infective virus tenfold in this time, and assuming no second cycle of infection in the diluted cells, it must be concluded that release of first-cycle virus continues from $16 \mathrm{hr}$. into the second day after infection. This might be due to slow continued release from a number of cells or great variation in the length of the latent period for different cells.

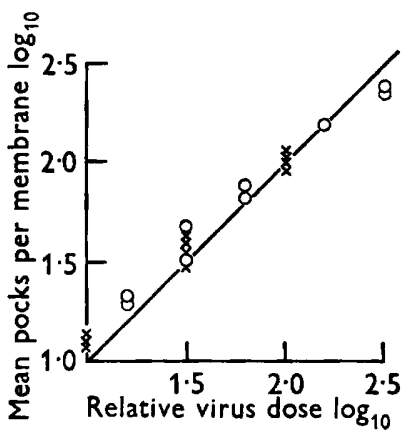

Fig. 1

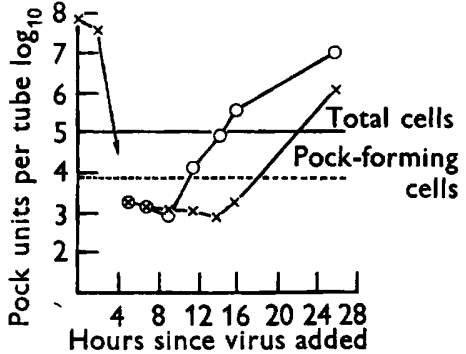

Fig. 2

Fig. 1. Mean pock count per CAM inoculated with increasing quantities of two herpes virus seed suspensions. Seed $\mathbf{A}=\times$; Seed $\mathbf{B}=0$.

Fig. 2. Growth of herpes virus in HeLa cells measured by pock counts. Monolayers exposed to 740 pock units/cell for $2 \mathrm{hr}$. (equivalent to about $55 \mathrm{HeLa}$ pfu/cell), excess virus then removed by washing and antiserum treatment. 'Total cells' indicate number of cells per monolayer determined by haemocytometer count. 'Pock-forming cells' indicate number of cells per monolayer which formed pocks when inoculated on to the chorioallantoic membrane during the latent period (see text). - $-0-$, EDTA fraction; $-x-x-$, medium, including virus in inoculum before and after adsorption.

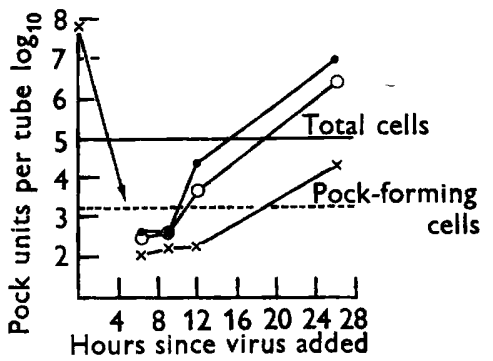

Fig. 3. Growth of herpes virus in HeLa cells measured by pock counts. Monolayers exposed to 740 pock units/cell for $2 \mathrm{hr}$. (equivalent to about $55 \mathrm{HeLa}$ pfu/cell), excess virus then removed by washing and antiserum treatment. 'Total cells' and 'pock-forming cells' as in Fig. 2. - - , Cell debris after freezing and thawing; - $-0-$, EDTA fraction; $-x-x-$, medium (inoculum after adsorption not shown).

An estimate of the amount of virus released/cell is only possible when the proportion of cells yielding virus is known. Only $2 \cdot 3 \%$ of the cells formed pocks in this experiment, indicating a release of 75 pock units/infected cell at $26 \mathrm{hr}$. and 144/cell at $50 \mathrm{hr}$. (not allowing for thermal inactivation). The real proportion of yielding cells may well be higher than that estimated, however (see below), and if so the amount of virus released per infected cell would be correspondingly lower. 


\section{Significance of EDT A fraction}

Virus appears in the EDTA fraction at the same time as in the fraction released by freezing and thawing. This EDTA fraction contains virus released during the process of detaching the sheet of cells from the glass by the chelating action of the EDTA. The virus released may have been extracellular but released from the cell surface by the EDTA. This would imply accumulation of virus at the cell surface for several hours before release into the medium. On the other hand, it is impossible to exclude damage to a few cells with

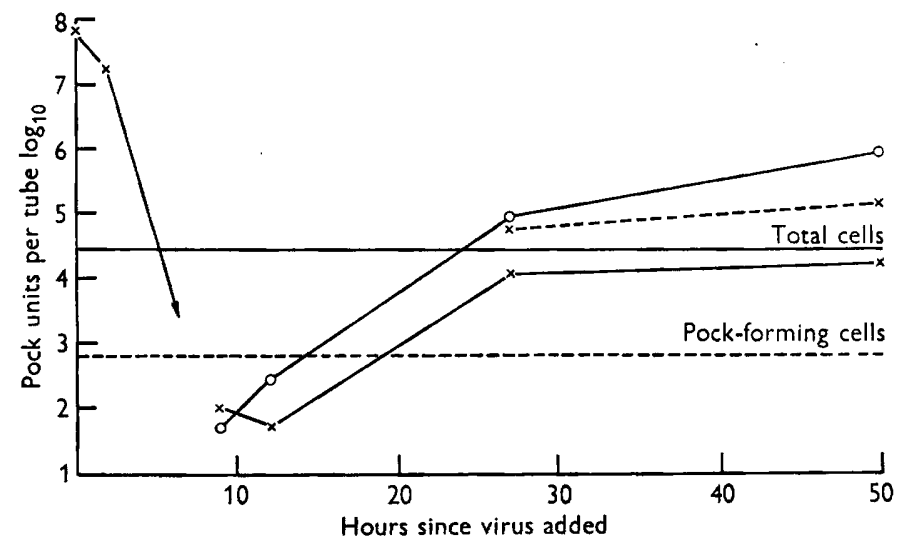

Fig. 4. Growth of herpes virus in HeLa cells measured by pock counts. Monolayers exposed to 740 pock units/cell for $2 \mathrm{hr}$. (equivalent to about $55 \mathrm{HeLa}$ pfu/cell), excess virus then removed by washing and antiserum treatment. 'Total cells' and 'pock-forming cells' as in Fig. 2. $-\mathrm{O}-\mathrm{O}-$, EDTA fraction; $-x-x-$, medium from original monolayer, including virus in inoculum before and after adsorption; $\cdots \times-\cdots \times-\cdot$, medium from diluted cells.

release of intracellular virus, particularly during the subsequent pipetting. In the experiment shown in Fig. 3 the concentration of virus in the cells at $12 \mathrm{hr}$. and later was higher than in the EDTA fraction and damage to one-sixth of the cells might release this quantity of virus.

An attempt was made to find whether EDTA had a specific activity in releasing surface virus. Cells infected $26 \mathrm{hr}$. previously were removed mechanically from the glass with a silicone rubber policeman into warm PBS. The cells were dispersed by gentle pipetting, divided into three portions, and centrifuged. The three pellets of cells were then suspended in PBS, 1/5000 EDTA and $0.5 \%$ Difco trypsin, respectively, for $30 \mathrm{~min}$. at $37^{\circ}$. After recentrifugation to remove the cells it was found that more virus had been released into

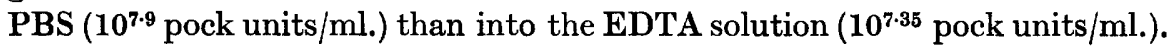
Very little virus was present in the trypsin fraction, but the latter even in high dilution caused many deaths amongst the chick embryos, so the titration was unsatisfactory.

This result does not suggest any specific activity of the EDTA but it still remains possible that alteration of the surface of the cell when it comes off the 
glass, releases extracellular surface virus. In the latent period in particular, the amount of virus in the cell debris is often lower than that in the EDTA fraction so cell rupture cannot account for the latter.

\section{Virus attachment}

The absence at the time of a satisfactory plaque technique in the host cells under study prevented a direct measurement of rate of adsorption, or of multiplicity of infection. Comparative titrations in eggs and HeLa cells had shown that 10 pock units of the HFEM strain of herpes virus grown in HeLa cells were needed to produce a $50 \%$ chance of infection in tube cultures of HeLa cells, and this has been confirmed by the plaque technique developed subsequently by Farnham (1958). Thus the great majority of virus particles are unsuccessful in HeLa cells in the sense that they do not initiate a cycle of multiplication. If the HeLa infective virus alone attaches to the cells, over $90 \%$ of the 'total' virus, i.e. pock units, should remain free and it would be impossible in practice to measure the fall in virus titre over and above loss from thermal inactivation. The following experiment showed that a much higher proportion of the 'total' virus became attached to the cells.

Monolayer cultures of $10^{6.55}$ and $10^{6.7} \mathrm{HeLa}$ cells in feeding bottles were exposed to virus at multiplicities of 18 and 0.0013 pock units/cell, respectively. Two ml. inocula were used, giving a depth of about $0.7 \mathrm{~mm}$. of fluid. Samples were removed at 5, 15, 60 and 120 min. for titration by pock counts. The low multiplicity was used in addition to the high dosage because it permitted the virus suspension to be inoculated directly on to the chorioallantoic membrane with only one further dilution step, thus increasing the accuracy of the titration. In addition, virus attachment to an incomplete sheet of HeLa cells was investigated by adding this small inoculum to $10^{6}$ cells spread over the same area of glass in a feeding bottle. As controls to detect thermal inactivation, the same amounts of virus were inoculated into empty bottles and also sampled.

The results are shown in Figs. 5 and 6. From the controls it will be seen that thermal inactivation was insignificant until the second hour. In the presence of the cells, however, about half the virus disappeared from the inoculum in $1 \mathrm{hr}$., with both low and high dosages of virus and with both complete and incomplete monolayers of cells. Further experiments showed that this was not due to release of virus-inhibitory substances from the freshly washed sheets of cells, or to greater virus inactivation at the slightly lower $\mathrm{pH}$ value main-

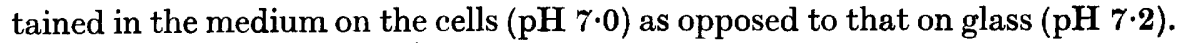
It is assumed that the virus is attached to the HeLa cells, but as we have seen, most of this pock-forming virus is unable to multiply in these cells.

\section{Residual virus in the latent period}

After the standard procedure of washing the infected cell sheets with PBS and two exposures to herpes antiserum, infective virus was always detected during the latent period in the cell fraction and in the medium. This residual virus usually constituted less than $0.01 \%$ of the original inoculum and, 
therefore, less than $0.02 \%$ of the 'total' virus which became attached. The virus which was detected in the medium appeared very soon after the antibody was removed. Similar treatment of virus in bottles with no cells left no detectable infectivity so the infectivity of the medium was not due to unneutralized virus detaching from the glass, and must, therefore, have been due to virus coming from the cell fraction. Replacement of medium at hourly intervals in the
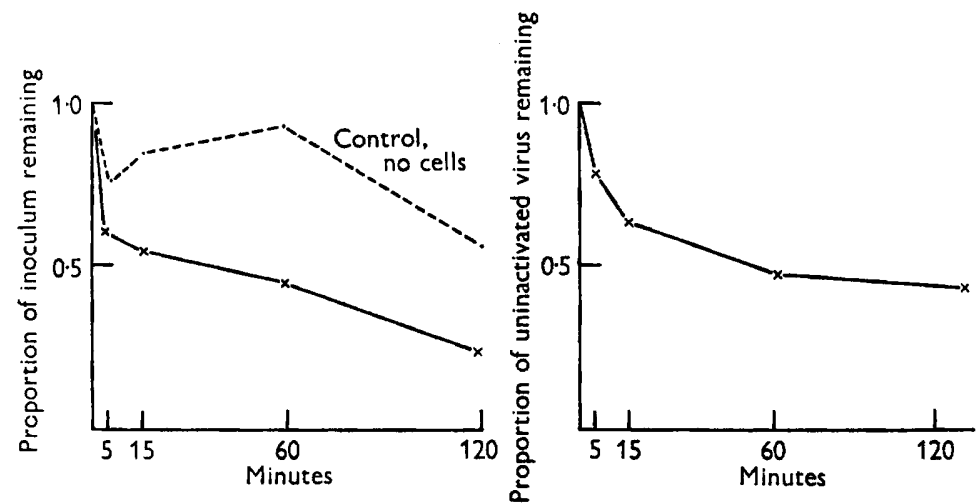

Fig. 5. Loss of pock-forming herpes virus in contact with HeLa cells. Monolayer of $10^{6.55}$ cells exposed to $10^{7 \cdot 81}$ pock units of virus (18 pock units/cell). Control with no cells shows thermal inactivation. Right-hand figure shows loss of virus after allowing for thermal inactivation.
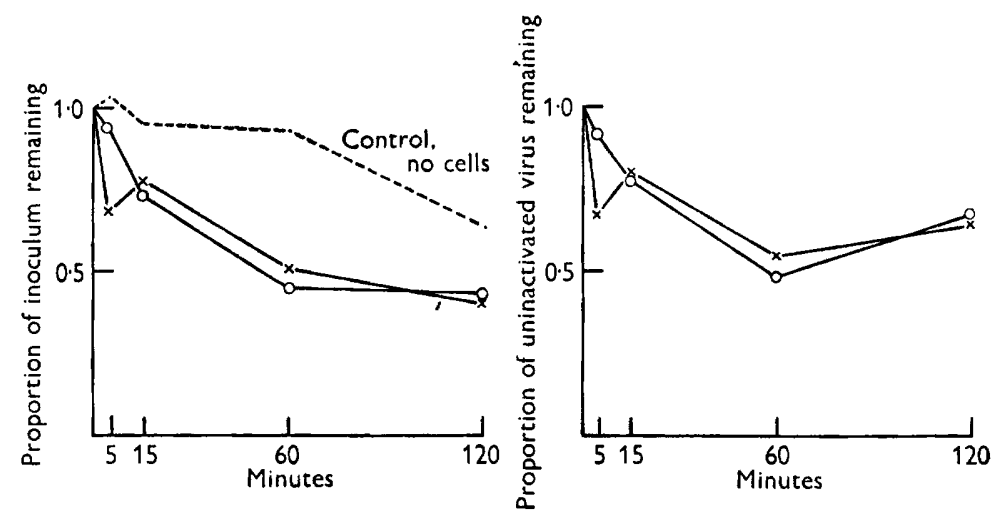

Fig. 6. Loss of pock-forming herpes virus in contact with HeLa cells. Complete sheet of $10^{8.7}$ cells and incomplete sheet of $10^{8}$ cells exposed to 3.81 pock units $(0.0013$ and 0.0065 pock units/cell respectively). $O-O, 10^{6}$ cells; $\times-\times, 10^{6 \cdot 7}$ cells.

latent period showed a slightly diminishing rate of release. When the cells were placed in a large volume of medium to decrease the chance of re-attachment, the total virus in the medium was not increased. There is thus no evidence that there is a state of equilibrium between the cell fraction and medium.

The virus associated with the cells usually amounted to less than one infectious particle/10 cells, and it can be found in the EDTA fraction or in the cell debris after disintegration. As already mentioned, it is not possible to 
exclude cell damage by EDTA with consequent release of intracellular virus, but in the latent period the cell debris after freezing and thawing ten times contains no more virus than the EDTA fraction. If the virus in the EDTA fraction was originally intracellular it would require disintegration of all the cells to release enough. Microscopic observation of the cells in EDTA solution showed 'bubbling' of an occasional cell but there was certainly no massive breakdown. It seems much more likely that this small amount of virus released by EDTA is at, or on, the surface of the cells, and is released when the cells round up after removal from the glass. The fact that it is not affected by treatment of the cells with herpes antibody does not rule this out when one considers the deep crypts in the HeLa cell surface in which virus may lie (see Stoker et al. 1958). Disintegration by freezing and thawing may, in fact, be releasing the same surface virus, because it is not possible to distinguish between virus in an invagination of the surface and true intracellular virus.

\section{Fate of the attached virus}

It has been seen that the virus recovered in the cell fraction in the latent period constitutes a very small proportion of that which attaches to the cells. The remainder may have been removed by the washing and immune serum treatment, and some of it may have lost its infectivity as a direct result of its contact with, or penetration of the cells. It was not possible to estimate directly the quantity of virus neutralized by antiserum but the amount removed mechanically by washing could be determined by replacing the immune serum with normal rabbit serum, and titrating the total amount of the virus in the nine changes of fluid. In two experiments 2 million cells were exposed to 52 and 14 pock units/cell, respectively, with similar results. These

Table 1. Fate of egg-infectious (pock-forming) virus after attachment to HeLa cells. Recovery expressed as \% of virus lost from inoculum

$\begin{array}{lrr}\text { Recovered in wash fluids : } & \% \\ & & \% \\ \text { 1st to 3rd } & 22 \cdot 0 & \\ \text { 4th to 6th } & 1 \cdot 5 & \\ \text { 7th to 9th } & 0 \cdot 5 & \\ & & 24 \\ \text { Reappeared in medium after washing } & 1 \\ \text { Recovered from cells : } & \\ \text { EDTA fraction } & 37 \\ \text { Cell debris } & 2 \\ \text { Inactivated during experiment } & 32 \\ \text { Deficit } & 100 \\ \text { Total lost from inoculum } & \end{array}$

are summarized in Table 1 in which recovered virus is expressed as a percentage of that lost from the inoculum. It will be seen that almost a quarter of the cell attached virus was recovered in the washing, most of it in the early washes. A control indicated that another small fraction might have been lost by thermal inactivation during the washing period, but there remained $73 \%$ of the attached virus which was not accounted for. Some of this was released after 
EDTA treatment of the cells but disintegration of the cells by freezing and thawing revealed a large proportion of this remaining virus in the cell debris. It still appears that there is a fraction of the attached virus which cannot be detected, but the extent or existence of this is difficult to measure because of the lack of accurate determination of the total amount lost from the inoculum.

The bulk of the attached virus is to be found in the cell debris, and it might be assumed that it enters the cells since it is not removed by repeated washing. It has been shown, however, that this virus is almost completely neutralized when the infected cells are exposed to antiserum. In the standard antiserum treatment less than $0.02 \%$ of the adsorbed virus is found in the cell debris compared to $41 \%$ after washing alone. We calculate that nearly all the infective virus found in association with the cells in the latent period is firmly attached at the cell surface, though antiserum-sensitive. The small amount of antiserum-insensitive virus may also be at the surface for reasons already stated, or it may be intracellular.

\section{Estimation of the proportion of cells yielding virus}

The object of exposing the cells to large doses of virus was to infect a high proportion of the cells simultaneously and make it easier to interpret changes during virus growth. Exposure to high multiplicity of pock units/cell, however, does not necessarily lead to infection of all the cells. The infectivity of the virus for HeLa cells is at least 10 times less than its pock-forming ability. It was, therefore, necessary to estimate the proportion of yielding cells. This was done by inoculating intact HeLa cells on to the chorioallantoic membrane and assuming that those which were infected would, in due course, release virus which would only form a single pock for each yielding cell. Monolayer cultures infected and washed by the standard treatment were removed from the glass with EDTA and pipetted to form a clump-free suspension. The cells were counted and diluted in medium to give estimated concentrations of 500 and $\mathbf{5 0 0 0}$ cells $/ \mathrm{ml}$. Two-tenth ml. volumes of cell suspensions with either 100 or 1000 cells, were then inoculated on to the chorioallantoic membrane. The remainder of each suspension was centrifuged and the cell-free supernatant fluids were also inoculated into groups of eggs. The number of pocks formed by the intact cell suspension, less the number in the cell-free supernatant fluid, gave the number of pock-forming cells, which were either carrying superficially attached virus, or alternatively, were yielding virus. The results of various estimations of the proportion of pock-forming cells are shown in Table 2. The input of virus in terms of HeLa pfu/cell has been calculated from the titre of the inoculum in pock units and the time of exposure.

Despite exposure to a very large number of pock units/cell which theoretically should have given a high multiplicity of infection, the growth experiments carried out in flat-sided tubes showed only a low proportion of pock-forming cells (see also Figs. 2-4). The results obtained after infection of monolayers growing in feeding bottles, however, gave somewhat higher number of pockforming cells in relation to input. This may have been due to the more even distribution of virus in a thin layer over the greater area of the monolayers in 
these bottles. The flat side of the test tubes was used and not only was the inoculum deeper but there was a large meniscus, and much of the fluid was in contact with bare glass; moreover, the cells were usually less evenly spread than in the feeding bottles. The proportion of pock-forming cells was not closely related to the input of virus, but the largest estimated multiplicity of infection led to the higher proportion of pock-forming cells. Perhaps a greater range

Table 2. Proportion of yielding cells

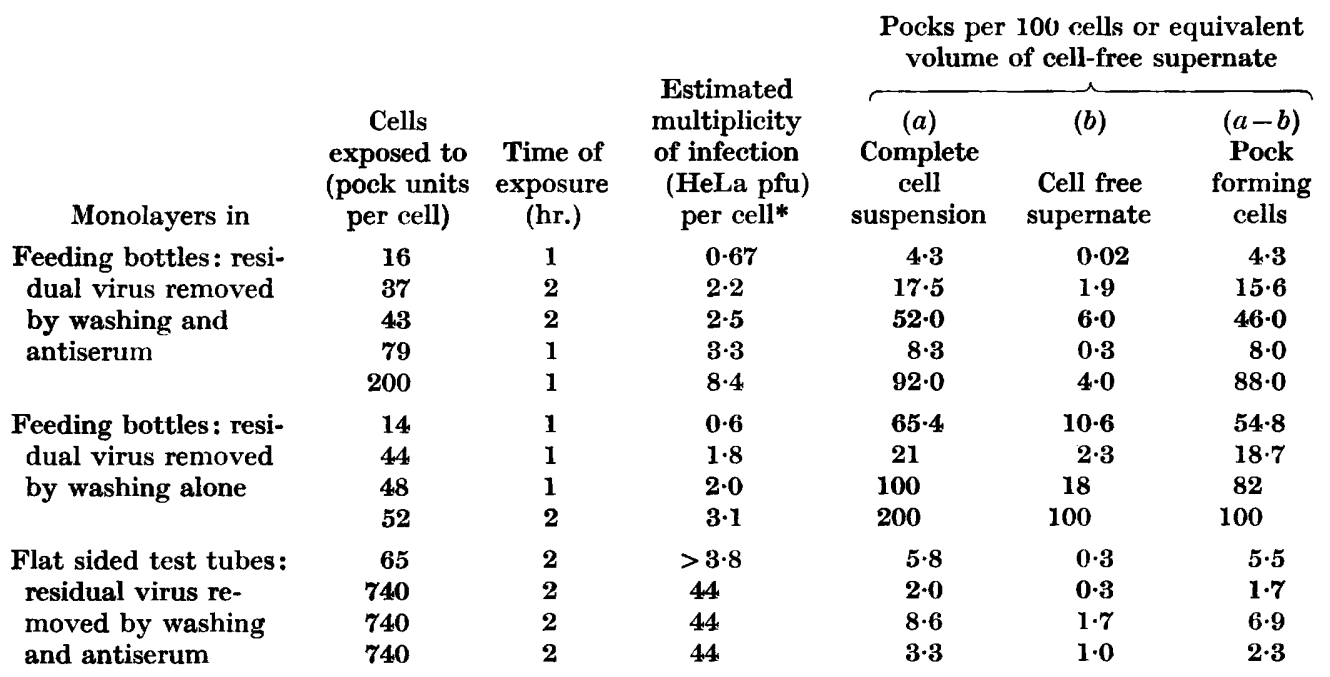

* Derived from ratio of pfu in HeLa cells to pock units on CAM (0.075) and proportion of pfu adsorbed to HeLa cells in $1 \mathrm{hr}$. or $2 \mathrm{hr}$.

of virus dose might have shown a relationship. Even in feeding bottles, however, the number of pock-forming cells was low considering the size of input, so various factors which might influence the estimation were examined.

A cell which released virus after the latent period might not have time to produce a pock in 2 days. However, leaving the eggs for an extra day before harvesting had no effect on the number of pock-forming cells. This does not exclude the possibility that many cells disintegrate on the membrane before the completion of new virus. Suspending and inoculating the cells at different times during the latent period also had no appreciable effect.

The herpes antibody used in the standard procedure for washing might remain attached to the cells, even after three further washes. This might then neutralize the virus as it left the cell. Increasing the number of washes from three to seven to remove the residual antibody had no effect on the number of pock-forming cells. On the other hand, eliminating the antibody from the washing procedure altogether certainly gave much higher proportions of pock-forming cells (see Table 2). Without antibody, however, it has already been shown that there is a large amount of virus in the cell fraction, which, being antiserum-sensitive, we assume to be superficially adsorbed virus from the inoculum. It is, therefore, probable that most of these cells give rise to 
pocks because of contaminating surface virus, and not through releasing newly formed virus. Disintegration of such cells in the latent period by freezing and thawing yields almost the same number of pocks as the intact cells.

It is also possible that with early antiserum treatment the efficiency of infection is low because, after attachment, it takes a long time for the virus on the surface to enter the cell and become antiserum insensitive. Monolayers were, therefore, not exposed to antiserum until $7 \mathrm{hr}$. instead of the customary 2-3 $\mathrm{hr}$. after infection. This did raise the proportion of pock-forming cells but the EDTA fraction was also increased, so it was difficult to exclude the possibility that the contaminating virus had become antiserum-insensitive though still extracellular, during the extra time, thus increasing the count of pock-forming cells. It is possible that even after antiserum treatment the figures given represent cells carrying contaminating virus alone and bear no relation to the number releasing fresh virus. Contaminating virus, however, should lead to pock formation whether the cell is intact or not, and several preliminary experiments showed that providing they had been treated with antiserum, disintegration of the cells by freezing and thawing produced fewer pocks than intact cells.

\section{Failure to detect infective virus in the latent period}

Since disintegration of the cells by freezing in the latent period gave fewer pocks than cells allowed to remain intact, it may be inferred that no intracellular virus was detected during the latent period of those cells which ultimately yield virus. Before this can be taken as evidence for a non-infectious phase in the growth of the virus, however, it is necessary to be sure that the cells, and especially the nuclei, are properly disintegrated and that the method of disintegration, and the resulting cell debris, have no damaging effect on the virus. Various methods of disrupting cells were investigated. Freezing and thawing ten times did not disintegrate the cells fully because the cell count was not decreased. Suspending cells in distilled water showed swelling and bubbling with blurring of the nuclei but no early decrease in count. Exposure of cells suspended in either medium or distilled water to a microblender with stainless steel blades at $20,000 \mathrm{rev} . / \mathrm{min}$. for $2 \mathrm{~min}$., however, decreased the cell count by $99 \%$ or more and left very few intact nuclei.

To find out whether normal cell debris, or the method of disintegration, decreased the infectivity of the virus, four batches of 1.8 million cells were mixed with a diluted virus suspension and each was immediately disrupted by one of the four methods described above. Cell debris and virus were inoculated on to the chorioallantoic membrane for assay, and untreated virus suspension was titrated as a control. The result (Table 3) showed no decrease in infectivity of the virus; in fact, the infectivity was slightly increased, though not as much as was found by Kaplan (1957) after similar treatment of herpes virus with rabbit kidney cells.

Disruption of cells in distilled water by the microblender seemed the method of choice and was used in the following attempt to detect intracellular virus 
Table 3. Effect of various methods of cell disintegration and the resulting cell debris on the pock-forming efficiency of herpes virus

Virus seed-untreated control

Pock units per ml.

Virus seed mixed with 1.8 million HeLa $\left(\log _{10}\right)$

cells, which were immediately exposed to one of the following methods of cell disintegration before assay:

Dilution in distilled water

10 cycles freezing and thawing

3.7

Microblender with cells in medium

Microblender with cells in distilled water

$4 \cdot 0$
$3 \cdot 8$
$3 \cdot 9$
$\mathbf{3 . 9}$

in the latent period. A monolayer of cells in a bottle was exposed for $2 \mathrm{hr}$, to 43 pock units $(3 \cdot 2 \mathrm{HeLa}$ pfu) of virus/cell, washed and treated with immune serum in the standard way, then replaced in medium at $37^{\circ}$. It is estimated that this represents an input equivalent to $2 \cdot 6 \mathrm{HeLa}$ pfu/cell. Seven hr. after inoculation the medium was sampled and the cells were suspended in EDTA solution, and counted. The cell suspension was diluted in medium to give 500 and 5000 cells $/ \mathrm{ml}$., and $0.2 \mathrm{ml}$. volumes were inoculated into eggs for estimation of the number of pock-forming cells. The remaining cells were centrifuged and the supernatant EDTA fraction removed for assay. The deposited cells were resuspended in distilled water and exposed to a microblender for $2 \mathrm{~min}$. The resulting homogenate was suitably diluted in medium before inoculation directly on to the chorioallantoic membrane. The results of this experiment are given in Table 4 . It will be seen that there

Table 4. Distribution of herpes virus in 3 million HeLa cells during latent period

$\begin{array}{lcc}\text { Inoculum } & \begin{array}{c}\text { Total } \\ \text { pock units } \\ \left(\log _{10}\right)\end{array} & \begin{array}{c}\text { Pock } \\ \text { units/100 } \\ \text { cells }\end{array} \\ \begin{array}{l}\mathbf{8 \cdot 1 1} \\ \text { Residual virus in latent period }\end{array} & 4300^{*} \\ \text { Medium } & 5 \cdot 23 & 5 \\ \text { EDTA fraction } & 5 \cdot 26 & 6 \\ \text { Disintegrated cell debris } & 5 \cdot 11 & 4 \\ \text { Intact cells (infective centres) } & 6 \cdot 14 & 46\end{array}$

* Estimated adsorption of HeLa infectious virus $=258 \mathrm{pfu} / 100$ cells.

remained in the latent period a small quantity of antiserum-insensitive virus distributed in the medium, the EDTA fraction and cell debris. We have already discussed the possibility that this is all derived from the cell surface. Forty-six out of 100 intact cells gave rise to pocks, but only four pocks could be found/100 cells disintegrated at $7 \mathrm{hr}$. Thus, some $42 \%$ of cells yielded virus in due course, even though no infective virus could be extracted from them during the latent period. 


\section{DISCUSSION}

When HeLa cells are exposed to large numbers of egg-infectious particles (pock units)/cell, about half the virus attaches to the cells in $1 \mathrm{hr}$., but only one pock-forming particle in twenty is able to initiate infection. About a quarter of the attached pock-forming virus can be removed mechanically by washing, but the bulk is firmly attached to the cells, where it can be detected after damaging the cells by freezing. This virus is nearly all neutralized by treating the cells with herpes antiserum so it is assumed to be at the surface. A much smaller quantity of virus, less than one particle/cell, is associated with the cells after antiserum treatment. Since this virus can be released as easily by suspending the cells in EDTA as by freezing and thawing, it is suggested that this is also surface virus, which perhaps lies in the deep invaginations of the HeLa cell membrane and so escapes neutralization. Since most of the 'total' pock-forming virus attaches firmly to the cell surface, the low efficiency of infection is presumably due to failure of the majority to penetrate, possibly due to a limited number of sites on the cell, or alternatively to heterogeneity in the virus population. This low efficiency of the HFEM strain has not been affected by thirty-four passages in HeLa cells.

One of the difficulties in this study has been the lack of a reliable estimate of the number of cells which undergo an infection and release new virus. In the absence of an infective centre count by a sufficiently sensitive plaque technique, the determination of the proportion of pock-forming cells has given variable figures, not closely related to the input of virus. It is possible that this is due to neutralization of the released virus by residual antiserum, but more washes did not increase the proportion of pock-forming cells. Determinations on infected cells which had not been exposed to antiserum gave high counts of pock-forming cells, but this appeared to be due to residual contaminating virus.

Associated studies on the release of herpes virus from single HeLa cells by Drs P. Wildy, M. G. P. Stoker \& R. W. Ross (unpublished) indicate that with deduced input multiplicities of between $0 \cdot 9$ and $3 \cdot 3,26 \%$ of cells yielded virus, but mostly not until the second day after infection. The proportion and the virus release/cell is not markedly increased when the cells are left free of antiserum, thus confirming that residual antibody is unlikely to be an important factor in decreasing the number of yielders. Direct comparison of the number of yielding single cells and the number of pock-forming cells from the same experiment shows that the estimate based on pock formation errs on the low side. Since leaving the eggs an extra day has no effect, the most likely explanation is that the cells do not all survive on the CAM long enough to make infective virus.

With these limitations in mind, however, and even if we assume the higher figure obtained from single cells, the proportion of those yielding is much lower than that expected from calculation of virus input based on plaque formation. Kaplan (1957), studying the growth of herpes virus in rabbit kidney cells, reported a low estimate of those yielding, judged by plating 
infected cells on rabbit kidney monolayers. It is possible that detachment of the cells from the glass, which is necessary for determining the proportion yielding, inhibits or delays virus release.

The evidence that infected cells contain no detectable virus when disintegrated in the latent period is similar to that produced by Wildy (1954), and also requires an estimate of numbers of infected cells. In several experiments it was impossible to detect sufficient virus in the cell debris in the latent period to account for the number of yielding cells especially since the latter is probably an underestimate. Though this suggests that there may be a noninfectious stage in the growth cycle it does not constitute proof unless it can be shown that the pock-forming efficiency of each physical virus particle is high. If the pock-forming efficiency of each particle is low, a few virus particles in a cell in the latent period, even though potentially infectious, would stand less chance of detection than many particles finally released by the cell. Unfortunately this information is not yet available for herpes virus.

Compared to the growth of herpes virus in chick fibroblasts (Gostling \& Bedson, 1956) and rabbit kidney cells (Kaplan, 1957), there is a long latent period of at least $9 \mathrm{hr}$. in HeLa cells before virus appears in the cell fraction (including possibly, the cell surface). Cells infected in the first cycle continue to release virus between 26 and $48 \mathrm{hr}$. after the original infection, a conclusion which is confirmed by the later studies on single cells. The relatively high rate of thermal inactivation, and the difficulty of knowing the proportion of infected cells makes it impossible to estimate accurately the particles released per cell.

The dynamics of herpes virus multiplication in HeLa cells reported in this paper may be considered with associated studies on the same virus-cell system. Thus, the first microscopic changes in the nucleus appear at $12 \mathrm{hr}$. after infection, and antigen can be detected in the nucleus by fluorescent antibody staining at $16 \mathrm{hr}$. (Ross \& Orlans, 1958). Chemical determination, however, shows a rise in deoxyribose nucleic acid in the nucleus as early as 6-9 hr. after infection, well before the appearance of new infective virus (Newton \& Stoker, 1958). It is not yet known whether this nucleic acid is a precursor of the virus or whether it is an inessential by-product of virus growth.

This work was supported by a grant from the Medical Research Council.

\section{REFERENCES}

Dulbecco, R. \& VogT, M. (1954). Plaque formation and isolation of pure lines with poliomyelitis viruses. J. exp. Med. 99, 167.

Farnham, A. E. (1958). The formation of microscopic plaques by herpes simplex virus in HeLa cells. Virology. In the Press.

Gey, G. O. (1949). Bull. Tissue Culture Ass. 16 March. quoted by R. C. Parker in Methods of Tissue Culture. 2nd ed., 1950, p. 81. New York: P. B. Hoeber, Inc.

GostLiNG, J. V. T. (1956). Intracellular site of developing herpes virus. Nature, Lond. 178, 1238.

Gostling, J. V. T. \& Bedson, S. P. (1956). Observations on the mode of multiplication of herpes virus. Brit. J. exp. Path. 37, 434. 
Kaplan, A. S. (1957). A study of the herpes simplex virus-rabbit kidney cell system by the plaque technique. Virology, 4, 435.

Nadaje, T., Tamm, I. \& Overman, J. R. (1955). A new technique for dropping the chorioallantoic membrane in embryonated chicken eggs. J. Lab. clin. Med. 46, 648.

Newton, A. \& Stoker, M. G. P. (1958). Changes in nucleic acid content of HeLa cells infected with herpes virus. Virology, 5, 549.

Ross, R. W. \& Orlans, E. (1958). The redistribution of nucleic acid and the appearance of specific antigen in HeLa cells infected with herpes virus. J.Path. Bact. 76 (in the press).

Scott, T. F. McN., Burgoon, C. F., Coriell, L. L. \& Blank, H. (1953). The growth curve of the virus of herpes simplex in rabbit corneal cells grown in tissue culture with parallel observations on the development of the intranuclear inclusion body. $J$. Immunol. 71, 385.

Scott, T. F. McN., Coriell, L. L., Blank, H. \& Gray, A. (1953). The growth curve of the virus of herpes simplex on the chorioallantoic membrane of the embryonated hen's egg. J. Immunol. 71, 134.

Stoker, M. G. P., Smith, K. \& Ross, R. W. (1958). Electron microscope studies of HeLa cells infected with herpes virus. J. gen. Microbiol. 19, 244.

Wildy, P. (1954). The growth of herpes simplex virus. Aust. J. exp. Biol. med. Sci. $32,605$.

Yoshino, K. \& Taniguchi, H. (1956a). Quantitative studies on the interactions between herpes simplex virus and ectodermal cell of chorioallantoic membrane of fertile hen's egg by means of the cover slip infection system. I. Adsorption of virus on to cells. Jap. J. med. Sci. Biol. 9, 303.

Yoshino, K. \& Taniguchi, H. (1956b). Quantitative studies on the interactions between herpes simplex virus and ectodermal cell of chorioallantoic membrane of fertile hen's egg by means of the cover slip infection system. II. Growth curve with special reference to the demonstration of non-infectious phase by removal of surface virus. Jap. J. med. Sci. Biol. 9, 321. 